\title{
Activism, academic bias and argument without nuance is harmful and potentially dangerous
}

\section{DHEERAJ KATTULA}

\begin{abstract}
Peter C Gøtzsche and Anders Sørensen in their article titled "Systematic violations of patients' rights and safety: Forced medication of a cohort of 30 patients" alleged violation of patient rights by psychiatrists with the use of force, thereby causing immense harm. In this commentary I try to understand their motivation, expose their bias, make an evidence based counterpoint, explore real life consequences of their views and make a case for nuanced discussion on complexities in mental health.
\end{abstract}

\section{Understanding motivations}

Peter C Gøtzsche and Anders Sørensen are from the Institute of Scientific Freedom, which, according to their website, works to preserve honesty and integrity in science and to help develop a better healthcare where more people will benefit; fewer will be harmed; and more will live longer in good health (1). The vision is very noble and shows that they value the interests of patients. Their other associated website has blog posts which argue against overdiagnosis of psychiatric disorders and over prescription of drugs (2). However their current study goes beyond reasonable critique as evidenced in their methodology and interpretation of results (3).

\section{Methodological issues}

In their study, Peter C Gøtzsche and Anders Sørensen studied the records for 30 consecutive patients who appealed decisions about antipsychotic medications to the Psychiatric Appeals Board in Denmark. They do not explain why these 30 were selected and do not report how many such appeals

Author: Dheeraj Kattula (askdheeraj@gmail.com), Associate Professor, Department of Psychiatry, Christian Medical College Vellore TN, INDIA and DM Addiction Psychiatry Resident, National Drug Dependence Treatment Centre, All India Institute of Medical Sciences, New Delhi.

To cite: Kattula D. Activism, academic bias and argument without nuance is harmful and potentially dangerous. Indian J Med Ethics. 2020 Oct-Dec;5(4) NS: 335-7.DOI: 10.20529/JJME.2020.114.

Manuscript Editor:Vijayaprasad Gopichandran

OIndian Journal of Medical Ethics 2020 are filed. In fact there were only 1488 complaints received by the psychiatric patients' complaints board in nearly a decade from January 1, 2010 to September 18, 2020 (4). It would be important to see these numbers in the light of total number of patients with mental illness who accessed care in Demark in the same time frame. It is necessary to see the extent of the problem that the authors allege is rampant and global. In the introductory section they assert that benefits from antipsychotics are uncertain by citing three books from "antipsychiatry" literature and one paper which looked at data from new drug trials (5)! They not only think that doctors are abusing power but they allege that they are hand in glove with their oversight body. Do they forget that it is the same body which gave them access to data for the current study? The content of the material which they studied was written down by the doctors whom the authors are trying to discredit. If the doctors were trying to play foul would they document the information which would incriminate them? This is not the only blind spot the authors have.

\section{Blind spots}

The authors describe instances of patients having adverse drug reactions which were recorded by the psychiatrists, who decided to continue with those drugs for reasons which were considered acceptable by the regulatory authority. Even in an audit, specialists in the field review the files and ask the treating doctors for explanations; but here the authors - who are not trained as psychiatrists - have passed judgement on the clinical decisions of psychiatrists. In fact, psychiatrists are trained to assess the potential risks and benefits of their interventions and non- intervention like any other health professionals.

The authors also recommend benzodiazepines and psychotherapy as options to be considered. They fail to note that even these interventions can be harmful. Even metaanalyses on the efficacy of psychotherapies suggest that up to half of the patients do not show significant change, and in about $5-20 \%$ of patients, adverse events could be expected (6) and that guidelines emphasise that benzodiazepines are not the first choice of treatment (7).

They also question the diagnosis of delusions by competent personnel who have examined the patients, when they themselves have not examined the patients. Is this not as unethical as diagnosing without examination? Psychiatrists are trained in mental status examination, as physicians are trained 
in physical examination and they diagnose delusions in a reasonably objective manner.

Most importantly, the authors turn a blind eye to the realities of mental illness. There is loss of insight in psychosis (8). Patients who have the condition do not believe that they have any problem. They suffer a lot because of their beliefs and can pose a threat to themselves and others. They are not to be punished for their behaviours but should be provided care. For example, the person described by the authors, who threatened to kill people, should not be tried in a court for his threats, but should be given treatment so that he could regain a sense of reality and control. Ignoring common knowledge about severe mental illness, the authors seem to take the content of the speech of the patients as "truth". This is as wrong as dismissing everything that a patient says as false.

The authors also seem to be unaware of the timeline of illness evolution and time lag in treatment response. When treatment starts early in the course of illness, there is a possibility of worsening of the symptoms after the start of treatment. This is not the effect of the medication but occurs despite the medication being given due to the evolving illness and the time lag before responding to the medication (9.10).

\section{A look at evidence}

The authors claim that there is no scientific basis for the use of antipsychotics. They cite some recognised methodological challenges in studies in psychiatry. However, they also try to conflate the issue by bringing up placebo controlled studies. It is important for us to know that doing placebo controlled studies in serious mental illness is not easy. In 2006, the Indian Journal of Medical Ethics published a discussion on a controversy arising from a placebo controlled study in India (11). The questions raised were addressed by the principal investigator (12). In that study, at the end point the proportion of patients whose severity of illness (CGI scale) was rated as "not ill," "mild," or "very mild" in the placebo arm, increased from $1 \%$ at baseline to $37 \%$. This does make a case for the presence of placebo response. However, in the drug arm the increase was from 0 per cent to 72 per cent, clearly showing much greater effect due to treatment with the drug (13). Scientists recognise that the adverse effects of drugs can affect blinding and that improvement can be because of the natural course of illness. However, the overwhelming evidence is in favour of antipsychotics.

It is considered unethical to include patients with severe illness like severe depression in placebo controlled trials, and therefore participants in clinical trials are those with illness of mild to moderate severity. The placebo response in these patients is likely to be greater than in those with severe illness. This leads to underestimation of efficacy in the literature. However, clinicians treating patients with severe depression witness the efficacy of antidepressant drugs.

\section{Deadly consequences}

I am an able bodied middle aged male with old parents, a middle aged wife, a sister and two young children. In the event of severe mental illness, I am capable of causing immense damage to them if my behaviour is not controlled with appropriate treatment. I hope, in such a situation, my friends and extended family would move me to a psychiatric facility. The doctors might have to coerce me to be admitted and take medication. I am likely to oppose this vehemently and might even complain to the mental health tribunal. I only hope they would recognise that what I am doing is because of my illness and would give me an opportunity to get better with appropriate treatments. I do not mind if I am coerced, as I hope to recover and regain my capacity to live a fulfilling life. Studies done in India on the perspectives of remitted psychiatric patients and caregivers about the use of physical restraints showed a widespread acceptance of restraints over seclusion; and of involuntary treatment with the consent of a family member and in the presence of the family member near the patient during the intervention $(14,15)$. If someone took the authors seriously and abandoned the provision of care for psychiatric patients under special circumstances, it would be a travesty of justice even though it is shrouded in terms from ethics and human rights. In India, The Mental Healthcare Act, 2017, protects the rights of persons with mental illness to receive care and respect of choice by taking a nuanced approach on capacity to take treatment decisions through informed consent, advance directives, nominated representatives and mental health review boards.(16)

\section{Academic bias}

Peter C Gøtzsche has long held beliefs against psychiatry especially regarding the validity of psychiatric diagnosis and the efficacy of psychiatric treatments. He has authored books on these issues. His two books have the term "deadly" referring to medicines (17) and "psychiatry"(18) in their titles He is likely to have an academic bias being invested in these beliefs, academic bias being the bias or perceived bias of any scholar. In a recent editorial, Arne May captures it well saying "The worst enemy of science is personal belief" (19).

\section{Matters of language and the need for nuance}

The authors have been extreme in their use of language throughout the article. Their negative attitude towards psychiatry as a discipline and psychiatrists as professionals is palpable. The content that they present from the perspective of patients is likely to be accurate. However, the sweeping generalisations, unfair criticism, condescending judgementality and baseless recommendations are more indicative of their bias than based on their data. It is clear that they want to advocate for patients. Their critique of overdiagnosis may have value. Issues of mental health like diagnosis, insight, judgement, capacity, risk assessment and treatment are complex. These need nuanced discussion not simple slogans from either social constructionists or biological reductionists. The authors should continue with their advocacy for 
psychiatric patients by being with them and learning from them in psychiatric hospitals, nursing homes, outpatient departments, day care facilities and community not from ivory towers of advocacy and academic institutes. In doing so they may gain a different perspective about the challenges faced by mental health professionals and thereby bring nuance into their argument.

Disclaimer: The views expressed by the author are personal.

\section{References}

1. Institute for Scientific Freedom website. [cited 2020 Sep 13]. Available from: https://www.scientificfreedom.dk/

2. Deadly medicines and organised crime website.. [cited 2020 Sep 13]. Available from:https://www.deadlymedicines.dk/home/

3. Gøtzsche PC, Sorensen A. Systematic violations of patients' rights and safety: Forced medication of a cohort of 30 patients. Indian J Med Ethics. Published online on August 12,2020[cited 2020 Sep 13]. Available from: https://doi.org/10.20529/IJME.2020.085

4. Danish Psychiatric Appeals Board. Statistics regarding the number of appeals to the Danish Psychiatric Appeals Board. 2010-20 (available with the author)

5. Khin NA, Chen Y-F, Yang Y, Yang P, Laughren TP. Exploratory analyses of efficacy data from schizophrenia trials in support of new drug applications submitted to the US Food and Drug Administration. J Clin Psychiatry. 2012 Jun;73(6):856-64. Doi: 10.4088/JCP.11r07539.

6. Klatte R, Strauss B, Flückiger C, Rosendahl J. Adverse effects of psychotherapy: protocol for a systematic review and meta-analysis. Syst Rev. 2018 08;7(1):135. Doi: 10.1186/s13643-018-0802-x

7. Lader M. Benzodiazepine harm: How can it be reduced? $\mathrm{Br} J$ Clin Pharmacol. 2014 Feb;77(2):295-301. Doi: 10.1111/j.13652125.2012.04418.x.

8. Raffard S, Bayard S, Capdevielle D, Garcia F, Boulenger J-P, Gely-Nargeot M-C. [Lack of insight in schizophrenia: a review]. L'Encephale. 2008 Oct;34(5):511-6. Doi: 10.1016/j.encep.2007.10.012. [French].

9. National Institute for Health and Care Excellence (NICE). Recommendations. Psychosis and schizophrenia in adults: Prevention and management. London, UK:NICE; 2014 Feb 12 [cited 2020 Sep 25]. Available from: https://www.nice.org.uk/guidance/cg178/chapter/1Recommendations\#subsequent-acute-episodes-of-psychosis-orschizophrenia-and-referral-in-crisis-2

10. National Institute for Health and Care Excellence (NICE). Recommendations | Depression in adults:recognition and management . Clinical guideline [CG90]. London, UK: NICE; 2009 Oct 28[cited 2020 Sep 25]. Available from: https://www.nice.org.uk/guidance/cg90/ chapter/Recommendations\#treatment-choice-based-on-depressionsubtypes-and-personal-characteristics

11. Patel V. Ethics of a placebo-controlled trial in severe mania. Indian $J$ Med Ethics. 2006 Jan- Mar;3(1):11-2. Doi: https://doi.org/10.20529/ IJME.2006.004

12. Khanna S. Response to Dr Vikram Patel. Indian J Med Ethics. 2006 JanMar;3(1):17-18. Doi: https://doi.org/10.20529/JMME.2006.006

13. Khanna S, Vieta E, Lyons B, Grossman F, Eerdekens M, Kramer M. Risperidone in the treatment of acute mania: double-blind, placebocontrolled study. Br J Psychiatry. 2005 Sep;187: 229-34. Doi: 10.1192/ bjp.187.3.229.

14. Anusuya S, Chandy SS, Ezhilarasu P, Tharyan P. Descriptive study to assess the needs, problems and opinions of caregivers of psychiatric patients with violent behaviour attending the department of psychiatry of Christian Medical College at Bagayam, Vellore. [Chennai]: Tamil Nadu Dr MGR Medical University; 2007.

15. Kattula D, Tharyan P. Perspectives of remitted psychiatric patients on physical restraints from a tertiary care psychiatric center from South India. Unpublished presentation at Annual National Conference of the Indian Psychiatric Society in Kolkata, India; 2008.

16. Ministry of Law and Justice, Govt of India. The Mental Healthcare Act, 2017. New Delhi: MoLJ; 2017 Apr 7 [cited 2020 Sep 25]; Available from: http://indiacode.nic.in/handle/123456789/2249

17. Gotzsche PC. Deadly medicines and organised crime: How Big Pharma has corrupted Healthcare. [cited 2020 Sep 25]. Place unknown: Routledge;2013 Aug 28.322 pgs.

18. Gotzsche PC. Deadly Psychiatry and Organised Denial. San Francisco, US: ArtPeople; 2015 Sep 1.365 p.

19. May A.The worst enemy of science.Cephalalgia. 2020 Sep 1;40(10):10156. Doi: https://doi.org/10.1177\%2F0333102420948521

\section{Be a part of IJME}

IJME invites readers to submit research studies, comments, case studies, reports, reviews, letters, as also poems, short stories, original paintings and photographs of print quality ( both in colour and $\mathrm{B} / \mathrm{W}$ ) to be considered for publication.

All submitted matter is subject to peer review.

Contributors are neither paid nor charged any fee for published matter. 